\title{
Absorption Spectra of Poly(1-vinylpyrene) in the Excited and Ionic States
}

\author{
Jun A. TAnaKa, ${ }^{\dagger \dagger}$ Hiroshi Masuhara, ${ }^{*, \dagger}$ and Noboru Mataga ${ }^{\dagger}$ \\ Department of Chemistry, Faculty of Engineering Science, \\ Osaka University, Toyonaka, Osaka 560, Japan \\ *Department of Polymer Science and Engineering, \\ Kyoto Institute of Technology, Matsugasaki, \\ Kyoto 606, Japan
}

(Received June 25, 1985)

\begin{abstract}
KEY WORDS Poly(1-vinylpyrene)/Laser Photolysis / Excited Singlet State / Triplet State / Cation / Anion / Excimer / Dimer Cation /
\end{abstract}

We studied electronic structure and dynamics of the excited and ionic states of polymers having aromatic groups in solution, using ps and ns laser photolysis methods. ${ }^{1,2}$ Whether electronic excitation, holes and electrons are localized on one chromophore or delocalized over several ones could be elucidated by analyzing the absorption spectra of the excited and ionic states. ${ }^{3-6}$ A relation between electronic structure, interchromophoric interaction and relative geometry of the corresponding chromophores have been made clear. Furthermore, a new photochemical behavior characteristic of polymers excited by a pulsed laser was reported for the first time. ${ }^{1}$ All these results have been obtained for polymers having $N$-carbazolyl and 9-phenanthryl groups as pendant or backborn chromophores. There has been no such study on the excited and ionic states in polymers other than these. Although pyrene is the most representative aromatic hydrocarbon showing intermolecular singlet excimer formation, ${ }^{7}$ only the $T_{n} \longleftarrow T_{1}$ absorption spectrum of the polymer with this chromophore was reported. ${ }^{8}$ In the present communication, absorption spec- tra of the excited singlet, triplet, cationic and anionic states of poly(1-vinylpyrene) are presented, as these are the basis for understanding interchromophoric interaction and photochemistry in polymers.

Poly(1-vinylpyrene) is the same as that reported elsewhere ${ }^{9}$ and was used after purification. Its mean degree of polymerization was estimated to be more than a few tens. $N, N$ Dimethylformamide (DMF) (Dotite Spectrosol) was used without further purification. The mean chromophore concentration was $\sim 5 \times 10^{-4} \mathrm{M}$. Unless otherwise noted, all solutions were flushed with $\mathrm{N}_{2}$ gas and the spectra were measured at room temperature. The ps transient absorption spectra were measured by using microcomputer-controlled ps $\mathrm{Nd}^{3+}$ : YAG laser photolysis system. ${ }^{10}$ The spectra of the triplet and ionic states in $\mu$ s time regions were obtained by using an excimer laser photolysis system where the $351 \mathrm{~nm}$ pulse with $14 \mathrm{~ns}$ fwhm was used as an excitation light source. ${ }^{11}$

Time-resolved absorption spectra in the ps and ns time regions are shown in Figure 1(a). Immediately after excitation a band shape

† To whom all correspondence should be addressed.

${ }^{\dagger \dagger}$ Present address: Production Engineering Research Laboratory, Hitachi Ltd., Totsuka, Yokohama 244, Japan. 


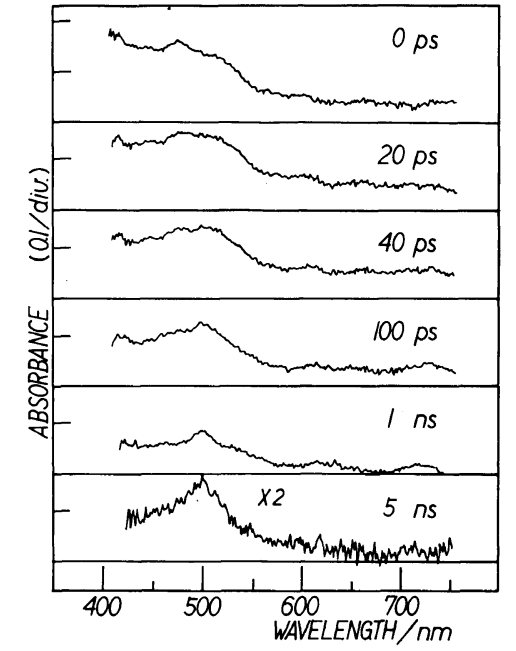

(a)

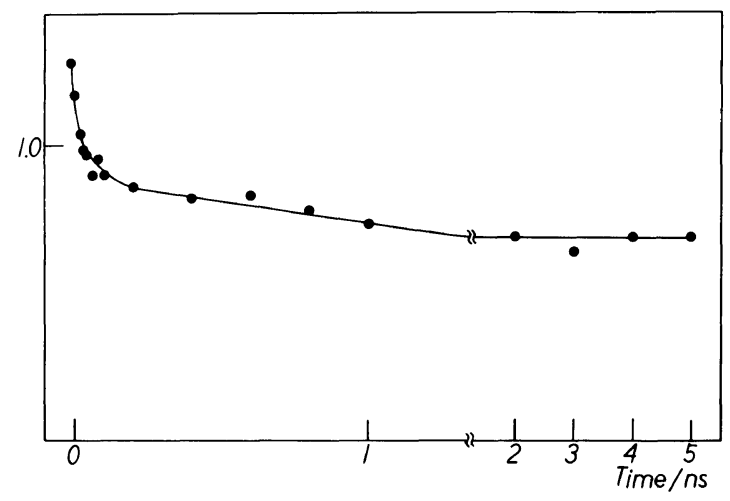

(b)

Figure 1. (a) Time-resolved absorption spectra of poly(1-vinylpyrene) in DMF in ps and ns time regions. (b) A ratio of absorbance at $475 \mathrm{~nm}$ over that at $500 \mathrm{~nm}$ as a function of the delay time.

descending to the long wavelength was observed, which is partly ascribed to an artifact brought about by temporal characteristic of the monitoring ps continuum. ${ }^{12}$ The peak at $475 \mathrm{~nm}$ was assigned to the $\mathrm{S}_{n} \longleftarrow \mathrm{S}_{1}$ transition of the monomeric excited state by comparing with reference data. ${ }^{13}$ The relative absorption intensity at $500 \mathrm{~nm}$ increases compared to that at $475 \mathrm{~nm}$ with an increase in delay time. The absorption peak at $100 \mathrm{ps}$ was at $500 \mathrm{~nm}$ and its band shape did not change up to $5 \mathrm{~ns}$. This is quite similar to the absorption spectrum of the pyrene excimer which was observed in the

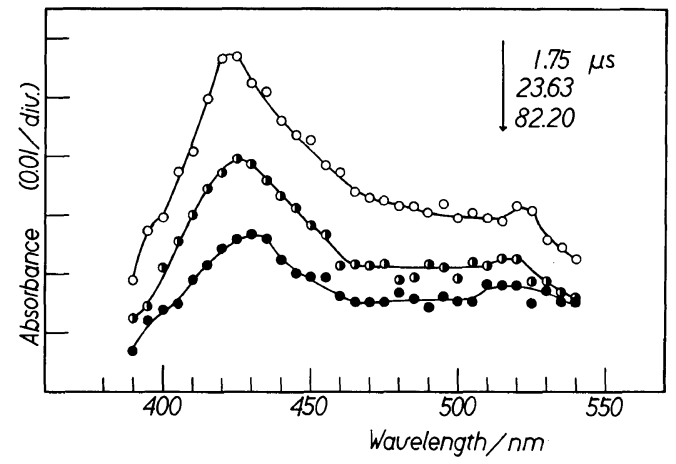

Figure 2. Time-resolved absorption spectra of poly(1vinylpyrene) in DMF in the $\mu$ s time region.

case of concentrated pyrene solution. No discussion is given here for the absorption at about $420 \mathrm{~nm}$, since the monitoring light intensity is weak around $400 \mathrm{~nm}$ and absorption intensity is rather low. No distinct excitation intensity dependence was observed, so that a contribution of ion radicals induced by multiphoton absorption is excluded. The timeconstant of the spectral change was estimated by plotting the absorbance ratio against the delay time, as shown in Figure 1(b). A quite rapid decrease up to a few tens of ps is considered to be due to a difference of arrival time of monitoring ps continuum, ${ }^{12}$ while a slow decay indicated that the excimer formation occurs with a time constant of several hundreds of ps.

The absorption spectrum of the triplet state is shown in Figure 2. At a few $\mu$ s after excitation the absorption maximum was observed around $420 \mathrm{~nm}$ and its band width is broader than that of 1-substituted pyrene. ${ }^{14}$ In the spectrum at late stages, a broad band with the maximum at $430 \mathrm{~nm}$ was observed. This spectral shape is almost identical with that of the former work ${ }^{8}$ and similar to that of mesoand racemic-bis[1-(1-pyrenyl)ethyl]ether. ${ }^{15}$ Since the latter was assigned to the triplet excimer of pyrenyl chromophores, the triplet excitation in this polymer is concluded to be stabilized as the excimer.

Cation and anion radicals of poly(1- 


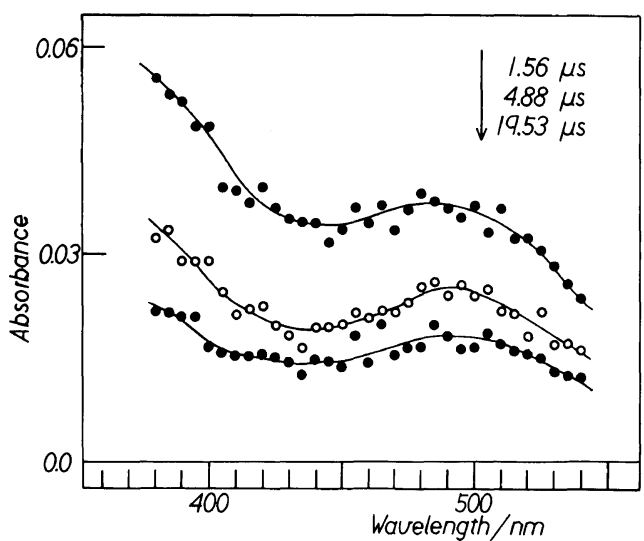

(a)

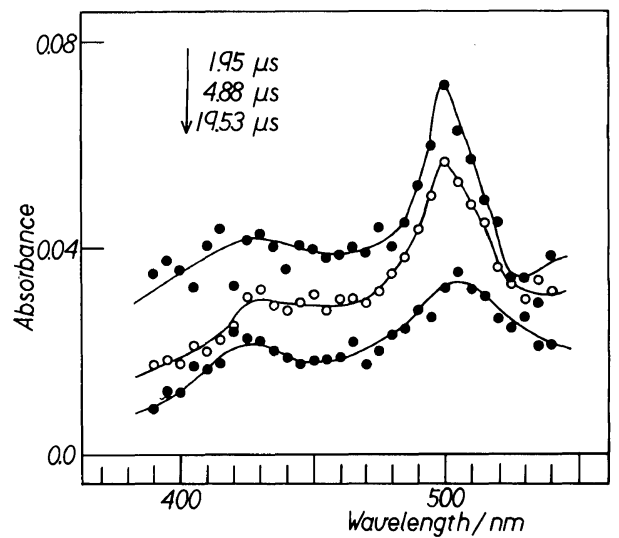

(b)

Figure 3. Time-resolved absorption spectra of poly(1vinylpyrene) cation (a) and anion (b) in DMF, which were produced by quenching the excited singlet state with $0.2 \mathrm{M}$ 1,4-dicyanobenzene and $1.0 \mathrm{M}$ Dabco, respectively.

vinylpyrene) were produced by quenching its excited state with 1,4-dicyanobenzene and 1,4diazabicyclo[2.2.2]octane (Dabco), respectively. The measurement was performed under air-saturated conditions to suppress the relative contribution of the $T_{n} \longleftarrow T_{1}$ band at $420 \sim 430 \mathrm{~nm}$. The spectra of both ion radicals are shown in Figure 3. The absorption bands of the polymer cation around $380 \mathrm{~nm}$ and $500 \mathrm{~nm}$ are similar to the bands of pyrene dimer cation. ${ }^{16}$ The formation process seems to be rapid since no spectral change was observed at these delay times. On the other hand, the spectrum of the polymer anion is identical with that of the pyrene monomer anion radical. A contribution of the bands of 1,4-dicyanobenzene anion and amine cation is considered to be negligible because their molar extinction coefficients are smaller compared to those of pyrene ion radicals. ${ }^{17,18}$

The absorption spectra of the excited and ionic states of poly(1-vinylpyrene) were measured for the first time under the same experimental condition. The singlet excitation and hole were stabilized as excimer and dimer cation of pyrenyl groups, respectively, while the interchromophoric interaction in the triplet state was weak. On the other hand, an interaction between anionic and neutral chromophores was repulsive inducing no spectral change. The present results are quite similar to those of $\operatorname{poly}(N$-vinylcarbazole) and related polymers as well as dimer model compounds. $^{6.17}$ The geometrical and electronic structures of pyrene excimers and dimer ions in the polymer were being studied.

Acknowledgment. The sample was kindly provided by Prof. Y. Shirota of Osaka University.

\section{REFERENCES AND NOTES}

1. H. Masuhara and N. Mataga, J. Luminescence, 24/25, 511 (1981) and papers cited therein.

2. H. Masuhara, Makromol. Chem. Supplement, 13, 75 (1985).

3. H. Masuhara, N. Tamai, N. Mataga, F. C. De Schryver, J. Vandendriessche, and N. Boens, Chem. Phys. Lett., 95, 471 (1983).

4. N. Tamai, H. Masuhara, and N. Mataga, J. Phys. Chem., 87, 4461 (1983).

5. H. Masuhara, K. Inoue, N. Tamai, and N. Mataga, Nippon Kagaku Kaishi, 14 (1984).

6. H. Masuhara, K. Yamamoto, N. Tamai, K. Inoue, and N. Mataga, J. Phys. Chem., 88, 3971 (1984).

7. J. B. Birks, "Photophysics of Aromatic Molecules," Wiley-Interscience, London, 1970, Chapter 7.

8. J. R. McDonald, W. E. Echols, T. R. Price, and R. B. Fox, J. Chem. Phys., 57, 1746 (1972).

9. M. Yokoyama, T. Tamamura, T. Nakano, and H. Mikawa, Chem. Lett., 499 (1972).

10. H. Masuhara, N. Ikeda, H. Miyasaka, and N. Mataga, J. Spectrosc. Soc. Jpn., 31, 19 (1982); H. 
Miyasaka, H. Masuhara, and N. Mataga, Laser Chem., 1, 357 (1983).

11. T. Saito, M. S. Thesis, Osaka University (1985).

12. This is ascribed to the difference of arrival times of monitoring ps continuum between $475 \mathrm{~nm}$ and $500 \mathrm{~nm}$; H. Masuhara, H. Miyasaka, A. Karen, T. Uemiya, N. Mataga, M. Koishi, A. Takeshima, and Y. Tsuchiya, Optics Commun., 44, 426 (1983).

13. T. Okada, M. Migita, N. Mataga, Y. Sakata, and S. Misumi, J. Am. Chem. Soc., 103, 4715 (1981).
14. H. Masuhara, J. A. Tanaka, N. Mataga, S. Egusa, M. Sisido, and Y. Imanishi, to be published.

15. H. Masuhara, J. A. Tanaka, N. Mataga, F. C. De Schryver, P. Collart, Polym. J., 15, 915 (1983).

16. A. Kira, S. Arai, M. Imamura, J. Chem. Phys., 54, 4890 (1971).

17. H. Masuhara, N. Tamai, N. Mataga, F. C. De Schryver, and J. Vandendriessche, J. Am. Chem. Soc., 105, 7256 (1983).

18. H. Schomburg, Thesis, Göttingen (1975). 